ARTIKEL RISET

http://citracendekiacelebes.org/index.php/INAJOH

\title{
Hubungan Status Sosial Ekonomi dengan Indeks Massa Tubuh (IMT) di Kecamatan Tamalanrea Kota Makassar
}

\author{
Meilinda Aji Syahputri ${ }^{1}$, Zulfahmidah ${ }^{2}$, Windy Nurul Aisyah ${ }^{3}$ \\ ${ }^{1}$ Program Studi Pendidikan Profesi Dokter, Fakultas Kedokteran, Universitas Muslim Indonesia \\ ${ }^{2}$ Departemen Ilmu Kesehatan Masyarakat, Fakultas Kedokteran, Universitas Muslim Indonesia \\ ${ }^{3}$ Departemen Ilmu Kesehatan Masyarakat, Fakultas Kedokteran, Universitas Muslim Indonesia \\ meilindaajisyahputri@gmail.com¹, zulfahmidah@umi.ac.id ${ }^{2}$, \\ windy.nurulaisyah@umi.ac.id ${ }^{3}$ \\ 087841707980
}

\begin{abstract}
ABSTRAK
Gizi merupakan salah satu faktor yang berperan penting dalam kemajuan suatu bangsa. Salah satu cara sederhana yang dapat digunakan untuk menentukan status gizi pada adalah dengan mengukur Indeks Massa Tubuh (IMT) atau Body Mass Index (BMI). Salah satu faktor yang berperan dalam menentukan status gizi seseorang adalah tingkat sosial ekonomi. Tingkat sosial ekonomi meliputi pendidikan, pendapatan, dan pekerjaan yang merupakan penyebab secara tidak langsung dari masalah gizi. Upaya peningkatan kesehatan baik berkaitan dengan kemampuan ekonomi dengan tingkat pendapatan dan kondisi lingkungan sosial anggota rumah tangga. Bagaimana ilmu-ilmu ekonomi berperan dalam lingkup tuntutan kesehatan setiap individu. Tujuan dari penelitian ini untuk mengetahui hubungan status sosial ekonomi dengan Indeks Massa Tubuh (IMT). Metode: Penelitian ini merupakan desain penelitian deskriptif. Data yang dikumpulkan menggunakan kuesioner. Data penelitian ini berupa variabel kategorik dari 2 kelompok sehingga menggunakan uji Chi Square. Hasil: Dari 84 sampel, berdasarkan perhitungan IBM SPSS Statistic 23 menggunakan uji analisis Chi Square diperoleh nilai $P$ value $(0,125) \geq 0,05$, maka $\mathrm{HO}$ diterima dan Ha ditolak artinya tidak ada pengaruh Pengaruh IMT terhadap faktor sosial ekonomi. Kesimpulan: Tidak ada hubungan status sosial ekonomi dengan Indeks Massa Tubuh (IMT) di Tamalanrea Kota Makassar.
\end{abstract}

Kata kunci : Indeks Massa Tubuh; Sosial Ekonomi; Masyarakat; Kecamatan Tamalanrea; Kota Makassar

\section{PUBLISHED BY :}

Yayasan Citra Cendekia Celebes

\section{Address :}

Perumahan Bukit Tamalanrea Permai

Blok D No.61 Kota Makassar,

Sulawesi Selatan, Kode Pos : 90211

Email :

inajoh@inajoh.org

Phone :

082346913176

\section{Article history :}

Received 09 Januari 2021

Received in revised form 15 Januari 2021

Accepted 16 Januari 2021

Available online 26 Februari 2021

licensed by Creative Commons Attribution-ShareAlike 4.0 International License. 
ABSTRACT

Background: Nutrition is a factor that plays an important role in the development of a nation. One simple way that can be used to determine nutritional status is to measure the Body Mass Index (BMI) or Body Mass Index (BMI). One of the factors that play a role in determining a person's nutritional status is the socioeconomic level. The socio-economic level includes education, income, and work which are indirect causes of nutritional problems. Efforts to improve good health are related to economic capacity with income levels and social conditions of household members. How economics plays a role in the health record of each individual. The purpose of this study was to see the status of the socio-economic relationship with Body Mass Index (BMI). Methods: This study is a descriptive research design. Data collected using a questionnaire. The data of this study were categorical variables from 2 groups so that it used the Chi Square test. Results: From 84 samples, based on the calculation of IBM SPSS Statistic 23 using the Chi Square analysis test, it was obtained that the P value (0.125) 20.05, then HO was accepted and Ha was rejected, meaning that there was no influence of BMI influence on socio-economic factors. Conclusion: There is no relationship between socioeconomic status and Body Mass Index (BMI).

Keywords: Body Mass Index; Social Economy; Community; Tamalanrea district; Makassar city

\section{PENDAHULUAN}

Gizi merupakan salah satu faktor yang berperan penting dalam kemajuan suatu bangsa. Salah satu cara sederhana yang dapat digunakan untuk menentukan status gizi pada adalah dengan mengukur Indeks Massa Tubuh (IMT) atau Body Mass Index (BMI). IMT dapat membantu untuk mengidentifikasi secara signifikan seseorang berisiko mengalami kelebihan berat badan. Perlu disadari oleh berat badan normal akan memberikan banyak keuntungan seperti penampilan yang baik, lincah, dan rendahnya resiko untuk terkena penyakit. Sebaliknya, bila berat badan kurang atau berlebih, maka akan lebih rentan terhadap berbagai penyakit dan dapat mempengaruhi fase kehidupan selanjutnya. ${ }^{1,2}$

IMT atau indeks Quatelet merupakan Indikator status gizi dalam bentuk pengukuran atau metode skrining yang digunakan untuk mengukur komposisi tubuh yang diukur dengan menggunakan berat badan dan tinggi badan yang kemudian diukur dengan rumus IMT. IMT adalah nilai yang diambil dari perhitungan antara berat badan (BB) dan tinggi badan (TB) seseorang. Di Indonesia IMT diklasifikasikan menjadi underweight $(<18,5)$, normal $(18,5-22,9)$, overweight $(23-24,9)$, obesitas 1 $(25-29,9)$, dan obesitas 2 ( 230$).{ }^{3,4}$

Salah satu faktor yang berperan dalam menentukan status gizi seseorang adalah tingkat sosial ekonomi. Tingkat sosial ekonomi meliputi pendidikan, pendapatan, dan pekerjaan yang merupakan penyebab secara tidak langsung dari masalah gizi. Upaya peningkatan kesehatan baik berkaitan dengan kemampuan ekonomi dengan tingkat pendapatan dan kondisi lingkungan sosial anggota rumah tangga dan bagaimana ilmu-ilmu ekonomi berperan dalam lingkup tuntutan kesehatan setiap individu. $^{5,6}$

Masalah gizi pada umumnya disebabkan oleh masalah ekonomi, kurangnya pangan, kurang baiknya kualitas lingkungan. Kekurangan gizi juga berhubungan erat dengan lambatnya pertumbuhan tubuh terutama pada anak, daya tahan tubuh rendah sehingga mudah sakit. Kelebihan gizi ditandai 
dengan berat badan lebih atau gemuk, beresiko terkena berbagai penyakit kronis, seperti Hipertensi, stroke, kolesterol, diabetes dan berbagai penyakit lainnya. Kekurangan gizi terjadi akibat asupan gizi di bawah kebutuhan sedangkan kelebihan gizi timbul karena asupan gizi melebihi kebutuhan. ${ }^{5}$

Bagi negara-negara yang sedang mengalami transisi gizi seperti Indonesia, masalah yang dihadapi juga mencakup kegemukan yang dialami akibat kemakmuran orang tuanya. Penelitian yang dilakukan Sebataraja tahun 2014 pada pelajar di daerah pinggiran Kota Padang juga menunjukkan bahwa terdapat hubungan yang signifikan antara status gizi dengan sosial ekonomi keluarga. Namun berbeda dengan penelitian yang dilakukan Kaunang tahun 2016 di Kecamatan Mandolang Kabupaten Minahasa, yang mengatakan bahwa tidak ada hubungan antara status sosial ekonomi baik itu pendidikan maupun pendapatan keluarga dengan status gizi. Hal ini membuat peneliti ingin mengetahui keterkaitan antara status sosial ekonomi dengan status gizi. ${ }^{8,9}$

Situasi gizi kurang di Makassar pada tahun 2013 berdasarkan profil Riskesdas tercatat sebanyak 2.825 orang $(24,92 \%)$ dengan jumlah penduduk tercatat sebanyak 1.272 .349 jiwa yang terdiri dari 610.270 laki-laki dan 662.079 perempuan. Tamalanrea merupakan kecamatan dengan berbagai kondisi sosial ekonomi dilihat dari bangunan dan lahan kosong dibanding kecamatan lain di Kota Makassar. Dengan pertimbangan tersebut maka peneliti tertarik mengadakan penelitian tentang, "Hubungan Status Sosial Ekonomi dengan Indeks Massa Tubuh (IMT) di Kecamatan Tamalanrea Kota Makassar". 9,21

\section{METODE}

Penelitian ini merupakan desain penelitian deskriptif. Lokasi penelitian di Kecamatan Tamalanrea Kota Makassar dan waktu penelitian dilaksanakan pada 14 - 28 November 2020. Populasi adalah Masyarakat di Kecamatan Tamalanrea Kota Makassar dengan teknik sampling menggunakan simple random sampling. Berdasarkan cara memperoleh data, data yang dikumpulkan menggunakan kuesioner. Analisis data yang diperoleh dilakukan menggunakan Microsoft Excel dan IBM SPSS 23. Data penelitian ini berupa variabel kategorik dari 2 kelompok sehingga menggunakan uji Chi Square. Hasil pencarian referensi dimasukkan ke aplikasi Mendeley menggunakan sistem Vancouver.

\section{HASIL}

\section{Analisis Univariat}

Pada tahap analisis ini adalah dilakukan analisis distribusi frekuensi dan persentase dari tiap-tiap variabel maupun distribusi krakristik variabel yang dianggap terkait dengan tujuan penelitian yang dimana hasilnya dalam bentuk tabel dapat dilihat sebagai berikut : 


\section{Karakteristik Responden berdasarkan Umur}

Tabel 1. Distribusi Responden berdasarkan Umur

\begin{tabular}{ccc}
\hline Umur & $\mathrm{N}$ & $\%$ \\
\hline 17 tahun & 4 & 4.8 \\
18 tahun & 3 & 3.6 \\
19 tahun & 8 & 9.5 \\
20 tahun & 13 & 15.5 \\
21 tahun & 5 & 6.0 \\
22 tahun & 4 & 4.8 \\
23 tahun & 18 & 21.4 \\
24 tahun & 16 & 19.0 \\
25 tahun & 5 & 6.0 \\
26 tahun & 2 & 2.4 \\
27 tahun & 1 & 1.2 \\
28 tahun & 1 & 1.2 \\
30 tahun & 1 & 1.2 \\
32 tahun & 1 & 1.2 \\
36 tahun & 1 & 1.2 \\
37 tahun & 1 & 1.2 \\
Jumlah & 84 & 100 \\
\hline
\end{tabular}

Sumber : Data Primer

Berdasarkan tabel 1 diatas menujukkan bahwa responden berumur 17 tahun ada sebanyak 4 responden (4.8\%), 18 tahun ada sebanyak 3 responden (3.6\%), 19 tahun ada sebanyak 8 responden (9.5\%), 20 tahun ada sebanyak 13 responden (15.5\%), 21 dan 25 tahun ada sebanyak 5 responden (6\%), 22 tahun ada sebanyak 4 responden (4.8\%), 23 tahun ada sebanyak 18 responden (21.4\%), 24 tahun ada sebanyak 16 responden (19\%), 26 tahun ada sebanyak 2 responden (2.4\%) dan masing-masing 1 responden untuk umur 27-37 tahun.

\section{Karakteristik Responden berdasarkan jenis kelamin}

Tabel 2 Distribusi Responden berdasarkan Jenis Kelamin

\begin{tabular}{ccc}
\hline Pekerjaan & N & $\%$ \\
\hline Perempuan & 64 & 76.2 \\
Laki-laki & 20 & 23.8 \\
Jumlah & 84 & 100 \\
\hline
\end{tabular}

Sumber : Data Primer 
Berdasarkan tabel 2 diatas menujukkan bahwa responden berjenis kelamin perempuan ada sebanyak 64 responden (76.2\%) dan pada laki-laki sebanyak 20 responden (23.8\%).

\section{Karakteristik Responden berdasarkan Indeks Massa Tubuh (IMT)}

Tabel 3 Distribusi Responden berdasarkan IMT

\begin{tabular}{ccc}
\hline IMT & $\mathrm{N}$ & $\%$ \\
\hline Underweight & 19 & 22.6 \\
Normal & 35 & 41.7 \\
Overweight & 13 & 15.5 \\
Obesitas 1 & 9 & 10.7 \\
Obesitas 2 & 8 & 9.5 \\
Jumlah & 84 & 100 \\
\hline
\end{tabular}

Sumber : Data Primer

Berdasarkan tabel 3 diatas menujukkan bahwa responden yang memiliki IMT underweight sebanyak 19 responden (22.6\%), selanjutnya IMT normal sebanyak 35 orang responden (41.7\%), sedangkan IMT overweight 13 responden (15.5\%), IMT Obesitas 1 sebanyak 9 responden $(10.7 \%)$ dan terakhir IMT Obesitas 2 sebanyak 8 responden $(9.5 \%)$.

\section{Karakteristik Responden berdasarkan Status Sosial Ekonomi}

Tabel 4 Distribusi Responden berdasarkan Status Sosial Ekonomi

\begin{tabular}{ccc}
\hline $\begin{array}{c}\text { Status Sosial } \\
\text { Ekonomi }\end{array}$ & $\mathrm{N}$ & $\%$ \\
\hline Rendah & 10 & 11.9 \\
Sedang & 64 & 76.2 \\
Tinggi & 10 & 11.9 \\
Jumlah & 84 & 100 \\
\hline
\end{tabular}

Sumber : Data Primer

Berdasarkan tabel 4 diatas menujukkan bahwa responden yang memiliki status sosial ekonomi rendah sebanyak 10 responden (11.9\%), sendangkan responden yang memiliki status sosial ekonomi sedang sebanyak 64 responden (76.2\%), dan terakhir responden yang memiliki status sosial ekonomi tinggi sebanyak 10 responden $(11.9 \%)$.

\section{Analisis bivariat (Analisis Pengaruh antar Variabel independen dan dependen).}

Pada tahap ini akan dilakukan analisis Pengaruh antara variabel dependen sesuai dengan tujuan penelitian diamana hasil pengolahannya sebagai berikut : 
Tabel 5 Pengaruh IMT dengan Sosial Ekonomi

\begin{tabular}{cccccc}
\hline \multirow{2}{*}{ IMT } & \multicolumn{3}{c}{ Sosial Ekonomi } & Jumlah & P (value) \\
\cline { 2 - 4 } & Rendah & Sedang & Tinggi & & \\
\hline Underweight & 4 & 10 & 5 & 19 & \\
Normal & 3 & 31 & 1 & 35 & \\
Overweight & 0 & 11 & 2 & 13 & 0.125 \\
Obesitas 1 & 1 & 7 & 1 & 9 & \\
Obesitas 2 & 2 & 5 & 1 & 8 & \\
Jumlah & 10 & 64 & 10 & 84 &
\end{tabular}

Sumber : Data Primer

Berdasarkan tabel 5 diatas menujukkan bahwa dari 84 sampel terdapat 4 responden yang underweight dengan status sosial ekonomi rendah, lalu terdapat 3 responden yang IMT normal dengan status sosial ekonomi rendah, selanjutnya terdapat 1 responden obesitas 1 dengan status sosial ekonomi rendah dan terdapat 2 responden obesitas 2 dengan status sosial ekonomi rendah.

Sedangkan di sisi lain responden yang memiliki status sosial ekonomi sedang, IMT tertingginya normal 31 responden, overweight 11 responden, underweight 10 responden, obesitas 1 ada 7 responden dan obesitas 2 ada 5 responden.

Terakhir responden yang memiliki status sosial ekonomi tinggi, IMT tertingginya underweight 5 responden, overweight 2 responden sedangkan IMT normal, obesitas 1 dan obesitas 2 masingmasing 1 responden.

Berdasarkan perhitungan IBM SPSS Statistic 23 menggunakan Uji Analisis Chi Square diperoleh nilai $P$ value $(0,125) \geq 0,05$, maka H0 diterima dan Ha ditolak artinya tidak ada pengaruh Pengaruh IMT terhadap faktor sosial ekonomi di Kecamatan Tamalanrea Kota Makassar.

\section{PEMBAHASAN}

Hasil analisis univariat (Tabel 1) diperoleh umur rata-rata yang lebih banyak mengisi kuesioner online ini adalah remaja dimana hal tersebut sesuai menurut Asosiasi Pengguna Jasa Internet Indonesia/APJII tahun 2018, pengguna internet di Indonesia berasal dari kelompok usia muda, umur 19 - 34 tahun dengan jumlah sekitar 49,52\% dari total pengguna, dan mahasiswa merupakan populasi terbesar dalam rentang usia tersebut. Pada tabel 2 diperoleh proporsi antara perempuan dan lelaki (2:1) lebih tinggi dibandingkan dengan data nasional (1:1). Hal ini dikarenakan lelaki cenderung tidak memiliki ketertarikan dalam mengisi kuesioner. ${ }^{10,11}$

Pada tabel 3 sebaran data Indeks Massa Tubuh, responden cenderung memiliki tubuh ideal berdasarkan standar Asia. Selain itu menurut tabel Standar Indeks Massa Tubuh menurut Umur 
nasional, data responden dalam batas normal. Prevalensi Normal dalam penelitian ini mencapai $41.7 \%$, kemudian disusul terbanyak kedua yaitu kategori underweight sebanyak $22.6 \%$ dibandingkan overweight $15.5 \%$ dikarenakan peneliti menggunakan standar WHO sesuai RISKESDAS bukan standar Asia yang batas underweightnya lebih rendah. ${ }^{12}$

Presentasi keluarga dengan status sosial ekonomi sedang pada penelitian ini lebih tinggi dibandingkan dengan data badan Pendidikan dan Pelatihan Keuangan (BPPK) tahun 2012. Peneliti beranggapan bahwa perbedaan ini diakibatkan oleh cara penilaian antara variabel yang berbeda dimana peneliti menggunakan kategori sosial ekonomi rendah, sedang, dan berat sedangkan BPPK menggunakan dua variabel yaitu menengah keatas dan menengah kebawah, juga pendapatan domestik bruto (pengeluaran perbulan) sebagai acuannya. ${ }^{13}$

Hasil analisis bivariat antata IMT dengan status sosial ekonomi menunjukkan tidak adanya hubungan yang signifikan dengan nilai $P$ value $(0,125) \geq 0,05$, maka H0 diterima dan Ha ditolak artinya tidak ada pengaruh Pengaruh IMT terhadap factor sosial ekonomi di Kecamatan Tamalanrea Kota Makassar. Hasil penelitian ini sesuai dengan hasil penelitian Yunida pada tahun 2009 menunjukkan tidak ada hubungan tingkat pendapatan keluarga dengan status gizi. Hasil penelitian Hidayati pada tahun 2012 juga menunjukkan tidak ada hubungan antara tingkat pendapatan dengan status gizi. Selain itu, hasil penelitian dari Astuti dan Sulistyowati pada tahun 2015 juga menunjukkan tidak adanya hubungan antara pendapatan dengan status gizi Kecamatan Godean Sleman. ${ }^{14,15,16}$

Sama halnya pula dengan penelitian yang dilakukan oleh Rimelfhi dkk pada tahun 2014 mengenai hubungan status gizi dengan status sosial ekonomi keluarga di daerah pusat dan pinggiran Kota Padang dimana hasilnya tidak menunjukkan adanya hubungan antara pendapatan keluarga yang kurang dari UMR (Upah Minimum Regional) masih dapat mencukupi kebutuhan makanan keluarga sehingga status gizinya normal. ${ }^{17}$

Tingkat pendidikan ayah dapat mempengaruhi dari jenis pekerjaan ayah yang memiliki pengaruh pada tingkat ekonomi keluarga yang juga mempengaruhi kemampuan orang tua memenuhi kebutuhan dan gaya hidup anak. Tingkat pendidikan ibu akan berkaitan dengan pengetahuan dan pemahaman ibu terhadap kesehatan, nutrisi, dan hal lainnya untuk anak. Hal ini akan mempengaruhi pola asuh, pengaturan nutrisi, serta pemilihan jenis makanan yang berkontribusi terhadap terjadinya obesitas pada anak. Pada ibu dengan tingkat pendidikan lebih tinggi sangat diharapkan terjadi peningkatan pengetahuan dan pemahan terhadap pola asuh dan nutrisi yang baik untuk anak dibandingkan ibu dengan tingkat pendidikan yang lebih rendah. Tetapi uji statistik hubungan IMT dengan status sosial ekonomi dimana pendidikan juga termasuk didalamnya didapatkan tidak bermankna pada penelitian ini. ${ }^{19}$ 
Tingkat pendapatan orang tua berkaitan dengan kemampuan orang tua untuk mencukupi kebutuhan, pemilihan jenis dan jumlah makanan, serta berpengaruh terhadap gaya hidup keluarga yang juga akan berdampak pada anak. Aritonang berpendapat bahwa pendapatan yang tinggi tidak selalu menjamin beragam dan bermutunya bahan pangan yang dikonsumsi tetapi dapat juga mengarah pada pemilihan bahan makanan yang lebih enak, siap santap, cepat, dan lebih banyak mengandung lemak, minyak, dan bahan lainnya yang dapat menyebabkan obesitas. Tetapi uji statistik penelitian ini menunjukkan tingkat pendapatan tidak mempengaruhi status gizi. ${ }^{20}$

Berbeda halnya dengan penelitian yang dilakukan oleh Hadi pada tahun 2015 Perbedaan hasil penelitian ini dapat dipengaruhi oleh berbagai faktor salah satunya perbedaan jumlah sampel yang cukup jauh antara penelitian ini dan penelitian yang dilakukan Hadi yaitu 84 dan 215 sampel. ${ }^{19,20}$

Kemiskinan dan kurang gizi merupakan suatu fenomena yang saling terkait, sehingga status gizi masyarakat erat kaitannya dengan upaya peningkatan ekonomi. Status sosial ekonomi juga sangat dipengaruhi oleh tingkat pendapatan keluarga, apabila akses pangan ditingkat rumah tangga terganggu, terutama akibat kemiskinan, maka penyakit kurang gizi (malnutrisi) pasti akan muncul. ${ }^{7}$

Peneliti berasumsi pada keluarga dengan status sosial ekonomi menengah ke atas kesejahteraan lebih terjamin, pengetahuan ibu terhadap gizi lebih baik dan perhatian ibu kepada anaknya lebih baik, sehingga sarapan lebih rutin terjadi pada keluarga dengan status sosial ekonomi menengah ke atas. Peneliti juga beranggapan adanya prilaku pergaulan remaja yang mengikuti lingkungannya sehingga beradaptasi dengan lingkungan pergaulannya, sehingga pengaruh status sosial ekonomi keluarganya tidak begitu berpengaruh.

Adanya keterbatasan dari tiap penelitian merupakan faktor perbedaan hasil dengan penelitian lain. Pengisian dalam kuesioner ini dilakukan secara online dimana tidak tipantau langsung oleh peneliti untuk mengukur tinggi badan dan berat badan yang nantinya digunakan untuk mengukur Indeks Massa Tubuh (IMT). Sehingga beberapa responden mengisi tinggi badan dan berat badan dimana terakhir responden ukur dimana waktu terakhir mengukur responden beragam bukan ukuran terbaru saat pengisian kuesioner. Penggunaan IMT untuk mengukur status berat badan di populasi dan menjadi skrining awal untuk mengidentifikasi adanya potensi permasalahan berat badan sudah tepat dipilih, namun tidak dapat dipungkiri pengukuran IMT masih kurang spesifik. IMT tidak dapat membedakan massa otot dengan lemak, sehingga perlu dilakukan pengukuran lebih lanjut yang lebih spesifik.

\section{KESIMPULAN DAN SARAN}

IMT atau indeks Quatelet merupakan Indikator status gizi dalam bentuk pengukuran atau metode skrining yang digunakan untuk mengukur komposisi tubuh yang diukur dengan menggunakan 
berat badan dan tinggi badan yang kemudian diukur dengan rumus IMT. Upaya peningkatan kesehatan baik berkaitan dengan kemampuan ekonomi dengan tingkat pendapatan dan kondisi lingkungan sosial anggota rumah tangga. Bagaimana ilmu-ilmu ekonomi berperan dalam lingkup tuntutan kesehatan setiap individu.

Pada Penelitian ini didapatkan bahwa tidak ada hubungan antara status sosial ekonomi dengan Indeks Massa Tubuh (IMT) dengan nilai $P$ value $(0,125) \geq 0,05$. Meskipun didapatkan hasil berbeda dari penelitian lain tetapi didapatkan pula banyaknya hasil yang sama dengan penelitian ini. Untuk kategori sosial ekonomi rendah didapatkan pendapatan keluarga yang kurang dari UMR (Upah Minimum Regional) masih dapat mencukupi kebutuhan makanan keluarga sehingga status gizinya normal. Aritonang berpendapat bahwa pendapatan yang tinggi tidak selalu menjamin beragam dan bermutunya bahan pangan yang dikonsumsi untuk pemenuhan gizi. Diharapkan bagi peneliti selanjutnya agar meneliti mengukur sendiri tinggi badan dan berat badan dari responden sehingga didapatkan hasil yang lebih akurat, selain itu untuk disarankan jumlah responden lebih banyak dan pemerataan untuk tiap golongan sosial ekonominya merata atau selisihnya tidak begitu jauh.

\section{UCAPAN TERIMA KASIH}

Puji syukur kepada Allah SWT, karena atas segala rahmat dan bimbingan-Nya penulis dapat menyelesaikan Karya Tulis Ilmiah ini. Penulis juga berterima kasih kepada peneliti-peneliti sebelumnya, dosen pembimbing, keluarga serta teman-teman yang senantiasa memberikan do'a dan dukungan sehingga penulisan hasil karya tulis ilmiah ini dapat terselesaikansemoga segala bantuan yang telah diberikan semua pihak di atas menjadi amalan yang bermanfaat dan mendapatkan balasan dari Allah SWT dan tugas ilmiah menjadi informasi bermanfaat bagi pembaca atau pihak lain yang membutuhkan.

\section{DAFTAR PUSTAKA}

1. Paulina, Aprilia. Hubungan Antara Status Sosial Ekonomi Keluarga dengan Status Gizi Kelurahan Bailang kecamatan Bunaken Kota Manado. Jurnal KESMAS, Vol. 8 No. 2, Maret 2019.

2. Ozdemir, Aysel., Kocuglu, Gulag., Hicran, Yildiz., Akansel, Neriman. (2016). Association of Body Mass Index With Eating Attitudes, Self Concept and Social Comparison in Hight School Student. International Journal of Caring Sciences. Volume 9, Nomor 1, Halaman 258-273.

3. Wahyu, Putra dan Solichathi, Amalia. Indeks Massa Tubuh (IMT) Mempengaruhi Aktivitas Remaja Putri SMP Negeri 1 Sumberlawang. GASTER Vol. XVI No. 1 Februari 2018

4. Kusumawardhani I. Hubungan Antara Indeks Massa Tubuh Dengan Status Periodontal. Politeknik Kesehatan Kementerian Kesehatan DI Yogyakarta. 2016;4(2):8-22. http://eprints.poltekkesjogja.ac.id/239/. 
5. Rompas, Karla dkk. Hubungan Antara Sosial Ekonomi Keluarga dengan Status Gizi pada Pelajar SMP Wilayah Kecamatan Malalayang 1 Kota Manado. PHARMACON Jurnal Ilmiah Farmasi - UNSRAT Vol. 5 No. 4 November 2016 ISSN 2302-2493

6. Puluhulawa, Idrus. Pengaruh Faktor Sosial Ekonomi terhadap Status Kesehatan Masyarakat Kecamatan Palu Selatan. e-Jurnal Katalogis, Volume I Nomor 3, Maret 2015 hlm 15-25

7. Azrul, Azwar. Metodologi penelitian kedokteran dan kesehatan masyarakat. Care Jurnal Ilmu Kesehatan. 2017;5(3):457. doi:10.33366/cr.v5i3.712

8. Khomsan, A. 2014. Peran Pangan dan Gizi Untuk Kualitas Hidup. Jakarta: Gramedia Widiasarana.

9. Kaunang, Carolina dkk. Hubungan Antara Status Sosial Ekonomi Keluarga dengan Status Gizi pada Siswa SMP Kristen Tateli Kecamatan Mandolang Kabupaten Minahasa. PHARMACON Jurnal Ilmiah Farmasi UNSRAT Vol. 5 No. 1 Februari 2016 ISSN $2302-2493$

10. Saputra, Andi. Survei Penggunaan Media Sosial di Kalangan Mahasiswa Kota Padang Menggunakan Teori Uses and Gratications. Jurnal Dokumentasi dan Informasi, 40(2) Desember 2019, Halaman: 207-216

11. Agung, Anak Gede dkk. Hubungan Status Sosial Ekonomi Keluarga dengan Kegemukan pada Remaja SMA di Denpasar. E-Jurnal Medika Udayana, Vol. 7 No. 3, Maret 2018: 99-106 ISSN: 2303-1395

12. RIKESDAS. 2013. Riset Kesehatan Dasar, Laporan Nasional 2013. Badan Penelitian dan Pengembangan Kesehatan, Departemen Kesehatan, Republik Indonesia. Desember 2013.

13. Widiatmanti H. 2015. Penghasilan Kelas Menengah Naik = Potensi Pajak?. Bdan Pendidikan dan Pelatihan Keuangan Kementrian Keuangan. Diakses 2 November 2020. Pada: http://www .bppk. kemenkeu.go.id/ publikasi/artikel/167artikel-pajak/21014penghasilan-kelasmenengah-naik-potensi-pajak.

14. Yunida, E. 2009. Hubungan Status Sosial Ekonomi Keluarga Dengan Berat Badan dan Tinggi Badan Anak Baru Masuk Sekolah Di SD Negeri No.06083 Kota Medan. Skripsi. Fakultas Kesehatan Masyarakat Universitas Sumatera Utara. (online), diakses 3 November 2020.

15. Hidayati, RN. 2012. Hubungan Tugas Kesehatan Keluarga, Karakteristik Keluarga dan Anak Dengan Status Gizi Balita Di wilayah Puskesmas Pancoran Mas Kota Depok. Tesis. Fakultas Ilmu Keperawatan. (online), diakses 3 November 2020. 
16. Astuti, F.D, dan Fitriyani, T. 2015. Hubungan Tingkat Pendidikan Ibu dan Tingkat Pendapatan Keluarga Dengan Status Gizi Anak Prasekolah dan Sekolah Dasar di Kecamatan Godean. Vol. 7. No. 1, KESMAS, (online), diakses 3 November 2020.

17. Rimelfhi, Lisbet dkk. Hubungan Status Gizi dengan Status Sosial Ekonomi Keluarga Murid Sekolah Dasar di Daerah Pusat dan Pinggiran Kota Padang. Jurnal Kesehatan Andalas. 2014; 3(2)

18. Repi, Amelia dkk. Hubungan antara Status Sosial Ekonomi dengan Status Gizi Anak Sekolah Dasar Kelas 4 dan Kelas 5 SDN 1 Tounelet dan SD Katolik St. Monica Kecamatan Langowan Barat. FKM UNSRAT, Manado, Hal: 1-9

19. Octari, Cici dan Indrawaty, Nur. Hubungan Status Sosial Ekonomi dan Gaya Hidup dengan Kejadian Obesittas pada Siswa SD Negeri 08 Alang Lawas Padang. Jurnal Kesehatan Andalas. 2018; 3(2). Access: http://jurnal.fk.unand.ac.id

20. Hadi SM, Sulityowati E, Mifbakhuddin. Hubungan pendapatan perkapita, pengetahuan gizi ibu dan aktivitas fisik dengan obesitas anak kelas 4 dan 5 di $\mathrm{SD} \mathrm{Hj}$. Isriati Baiturrahman kota Semarang. Jurnal Kesehatan Masyarakat Indonesia. 2017; 2(1):7-12.

21. Novi, Hertien dkk. Pengetahuan Gizi Ibu dan Sosial Ekonomi Keluarga terhadap Status Gizi Balita Umur 6-24 Bulan di Kecamatan Tamalanrea Kota makassar. Media Gizi Pangan, Vol. 25, Edisi 1, 2018. 